\title{
AN APPROACH TO RETROPERITONEOSCOPIC UROLOGICAL SURGERY
}

\author{
MD. FAZAL NASER ${ }^{1}$, MD. ABUL HOSSAIN ${ }^{1}$, MD. SHAFIQUL AZAM ${ }^{1}$, ABM MUKSUDUL ALAM $^{2}$, UTTAM \\ KUMAR BARUA ${ }^{3}$, KP SAHA ${ }^{4}$, K KARMAKAR ${ }^{5}$, MD. SHOHRAB HOSSAIN ${ }^{1}$
}

${ }^{1}$ Dept. of Urology, Shaheed Suhrawardy Medical College, Dhaka. ${ }^{2}$ Dept. of Anesthesiology, Shaheed Suhrawardy Medical College, Dhaka, ${ }^{3}$ Director, Shaheed Suhrawardy Medical College Hospital, Dhaka, ${ }^{4}$ Dept. of Surgery, Shaheed Suhrawardy Medical College, Dhaka. ${ }^{4}$ Dept. of Anesthesiology, NICVD, Dhaka

\begin{abstract}
:
Objectives: To determine the safety and efficacy of retroperitoneoscopic surgery for renal, ureteral and adrenal diseases.

Methods: Since October 2013, 62 patients (22 to 65 years old) have undergone retroperitoneoscopic renal, ureteral and adrenal surgery. Patients were included according to the inclusion criteria depending on the specifying disease and operation. Patient were appropriately evaluated and counseled before operation. The retroperitoneal space was created by handmade balloon dissection.

Results: Average kidney size was $85 \mathrm{~mm}$ (range 50 to 1720) in simple nephrectomy cases, and average renal tumor size was $64 \mathrm{~mm}$ (range 48 to 73). Simple nephrectomy in 10, radical nephrectomyin 09, nephrouretectomy in 8 , adrenalectomy in 1, decortication of renal cyst in 11 , pyeloplasty in 06, transposition of retrocaval ureter in 06 and ureterolithotomy in 11 cases. Operating time varies from $35 \mathrm{~min}$ to $221 \mathrm{~min}$, depending upon the procedure. Hospital stay varies from 2 to 7 days in different cases. Conversion from the laparoscopic procedure to open surgery was required in 3 cases. Peritoneal rent occurred in only 2 patients.
\end{abstract}

Conclusions. The laparoscopic retroperitoneal approach is safe and effective for different types of renal, ureteral and adrenal surgery. Perioperative morbidity and hospital stay are reduced.

Keywords: Retroperitoneoscopy, Urological Surgery

Bangladesh J. Urol. 2016; 19(1): 3-12

\section{Introduction:}

Interest in laparoscopy among urologists of Bangladesh is relatively recent than other parts of the world. With the co-operation from native and foreign urologist, use of laparoscopy in urology is gaining momentum slowly but steadily. More complex operations such as nephrectomy and adrenalectomyare now being regularly performed in different urological centres of Bangladesh.

Laparoscopic renal, adrenal and ureteral surgery is commonly performed by the transperitoneal approach.Primarily, this is because the transperitoneal route offers a larger working space and well defined

Correspondence : Md. Fazal Naser, Shaheed Suhrawardy Medical College, Sher-e-Bangla Nagar, Dhaka, Bangladesh, Email : fazaltamim01@yahoo.com anatomic landmarks. However urologists have historically favored a retroperitoneal approach when using open surgical interventions for both renal and adrenal lesions. By maintaining a retroperitoneal surgical field for infectious or malignant processes, the risk of peritonitis or peritoneal seeding is minimized. In addition, this approach helps control and efficiently drain any urinary leakage immediately after renal reconstructive procedures (eg, pyeloplasty, anatrophic nephrolithotomy with infundibuloplasty, partial nephrectomy). Indeed, laparoscopic nephrectomy for benign disease increasingly is being performed by the retroperitoneal approach at various urologiclaparoscopic centers worldwide[1].

Since October 2013 , we are successfully performing different types of retroperitoneoscopic surgery in the 
department of urology of Shaheed Suhrawardy Medical College Hospital and other three private hospitals in Dhaka city.Within this period we have tried 62 different Retroperitoneoscopic urological procedure, 3 needed conversion. In this article we like to share our two years' experience of techniques, complications and outcome of retroperitonescopic surgery.

\section{Material and Methods \\ Patients}

Since October 2013, 62 patients have undergone retroperitoneoscopy for renal, ureteral and adrenal surgery at Shaheed Suhrawardy Medical College Hospital and three other private hospitals in Dhaka city. Inclusion criteria were fixed according to the specific disease and operation.

Contraindications to the retroperitoneal approach were previous lumbar or retroperitoneal surgery and large renal or adrenal tumors. Previous renal infection was considered a relative contraindication.

\section{Preparation:}

All patients were properly evaluated physically. Routine and special investigations like ultrasonogram, intravenous urogram, CT urogram, DTPA renogram and FNAC were done in area of need. After proper evaluation, those patient who fulfill the inclusion criteria were selected for retroperitoneoscopic surgery. All patients were informed that it was a new type of laparoscopic procedure and, though reasonably safe, might be associated with major complications and that it might fail as a result of technical or anatomical reasons leading to conversion as a open surgery. A simple enema in the morning was advised as a loaded colon might require a greater insufflation pressure to keep the space open during retroperitoneoscopy. Prophylactic chemoprophylaxis was done in all cases.

\section{Retroperttoneoscopic Approach}

Necessary instruments

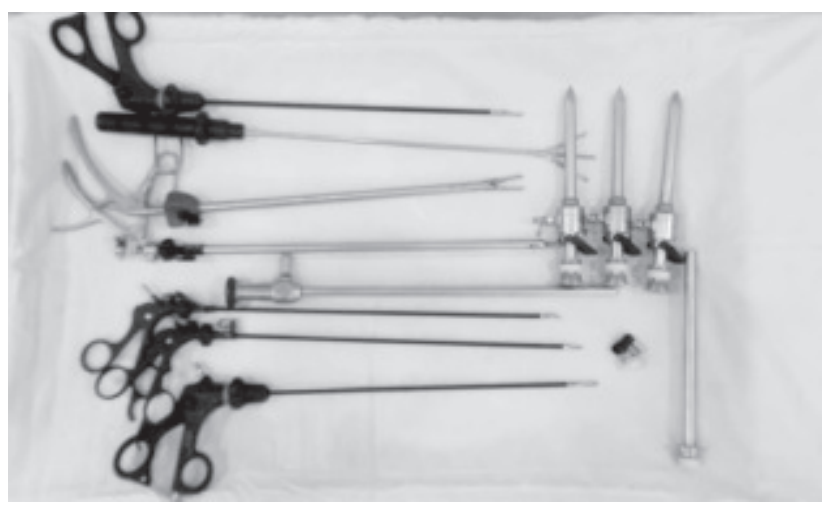

Fig.-1: Instruments used during retroperitoneoscopic surgery
One 10-mm 30 laparoscope.

One hand made balloon dissector using surgeon's glove's double cuff mounted on a $14 \mathrm{fr}$ feeding tube.

One $50 \mathrm{cc}$ disposable syringe

Three 10-12-mm trocars (Reusable/ Disposable).

One 5-mm electrosurgical monopolar scissors.

One 5-mm electrosurgical hook.

One 5-mm atraumatic grasping forceps (single jaw movable)

One 5-mm right-angle dissector.

One 10 or 5-mm three-pronged reusable metal retractor (fan-type)

One 11-mm Endoclip applicator with disposable clip cartridges

One Weck clip applicator with disposable clip cartridges (Weck Systems)

One 5-mm irrigator/aspirator

One Harmonic Scalpel (optional

\section{Patient Position}

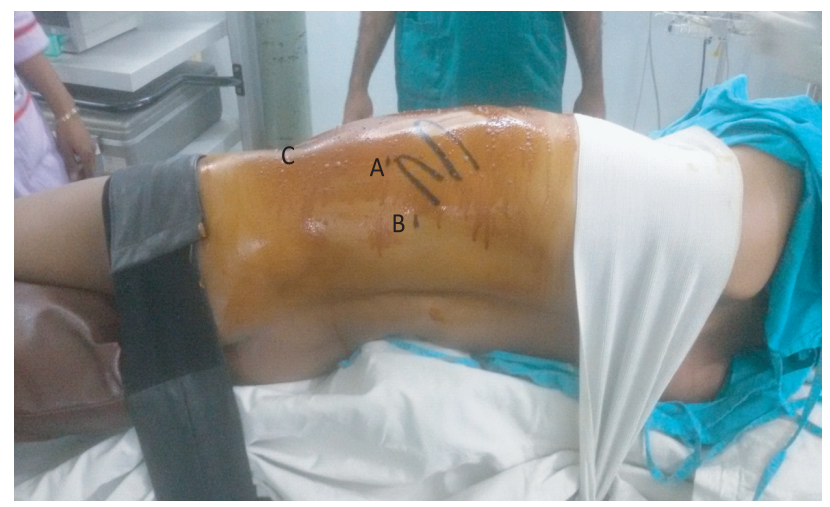

Fig.-2: Port placement during left retroperitoneoscopy radical nephrectomy. (A) primary $10-12 \mathrm{~mm}$ port is placed at the tip of 12th rib. (B) $10 \mathrm{~mm}$ port is placed at junction of lateral border of the erector spinae muscle with underside of 12th rib. (C) 10-12 $\mathrm{mm}$ port is placed two finger breadths cephalad to iliac crest, between mid and anterior axillary lines.

Operating table in a $90^{\circ}$ full flank position. All bony prominences were meticulously padded and extremities carefully placed in neutral position to minimize postoperative neuromuscular sequelae (Fig : 2) The kidney bridge is elevated moderately, and the operating 
table is flexed somewhat to increase the space between the lowermost rib and the iliac crest.

\section{Preparation of the handmade balloon dissector}

As the commercial balloon for creating the retroperitoneal space is costly. So we have developed our own balloon modifying the Gaur's technique. Here we have used the double cuff of sterile glove's rather than the finger of the gloves. First we have invaginated one cuff into another, then one end is tied with a piece of silk. Then the tied end turns inside out, so that the stiffness of the balloon is diminished. Then through another open end a $14 \mathrm{Fr}$ feeding tube of appropriate length is introduced, this end of the balloon is double tied with a silk so that there is no air leakage. A $50 \mathrm{cc}$ disposable syringe is connected to the other open end of the feeding tube. A medium sized haemostat is applied over the feeding tube intermittently to prevent the air leakage during the inflation of the balloon.

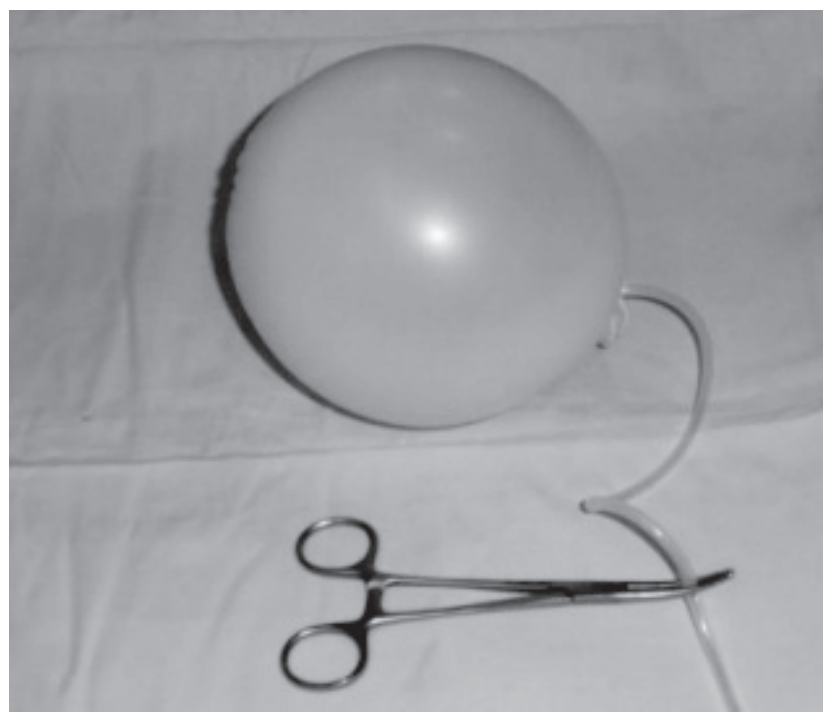

Fig.-3: Handmade glove's double cuff balloon dissector

\section{Operation Room Set-Up}

The surgeon and the camera operator (assistant) stand facing the patient's back. The surgeon stands towards the patient's feet, while the assistant stands toward the patient's head. The cart holding the video monitor, $\mathrm{CO}_{2}$ insufflator, light source, and recorder were placed opposite the surgeon.

\section{Retroperitoneal Access, and Port Placement}

The primary port is placed just below the tip of the 12th rib in the posterior axillary line. A horizontal $1.5-\mathrm{cm}$ skin incision is made. Using $\mathrm{C}$-shaped retractors, the flank muscle fibers are bluntly separated. Entry is gained into

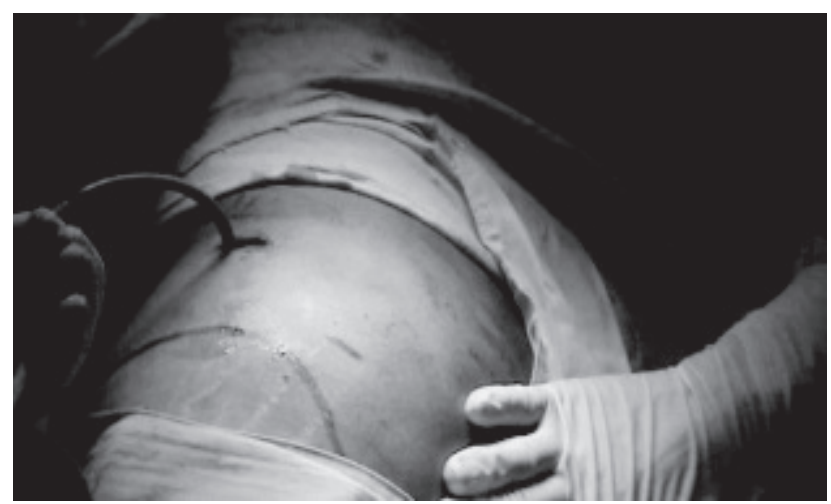

Fig.-4: Creating the Retroperitoneal space using the handmade balloon dissector

the retroperitoneal space by gently piercing the anterior thoracolombar fascia with the haemostat. Limited finger dissection of the retroperitoneum is performed in a cephalad direction, remaining immediately anterior to the psoas muscle and fascia, and posterior to the Gerota's fascia to create a space for placement of the balloon dilator. At this juncture the tip of the lower pole of the kidney can often be palpated by the finger. Then the balloon is inserted. A $50 \mathrm{cc}$ disposible syringe is connected to the other end of balloon dissector. The volume of air instilled into the balloon is typically 800 $1200 \mathrm{~mL}$ in adults. The balloon dilatator is place outside Gerota's fascia (i.e.in the pararenal space between the psoas muscle posteriorly and Gerota's fascia anteriorly) effectively displaces the Gerota's fascia covered kidney anteromedially, allowing direct access to the posterior aspect of the renal hilum. The advantage of the handmade balloon is the negligible cost, as we are using double cuff so it can create more space maintaining a low pressure and virtually no chance of rupture the balloon. The inflated balloon is maintained for 3-5 minutes so as to create adequate space in the retroperitoneum and secure hemostasis.

Then the balloon was re-moved and the primary port, a $10 \mathrm{~mm}$ port introduced into the retroperitoneal space. This can-nula was stabilized with 2 or 3 sutures of 1-0 silk, which included the parietal musculature and the thoracolumbar fascia in order to prevent surgical emphy-sema and accidental dislodgement during the procedure. A carbon-dioxide pneumo-retroperitoneum was estab-lished through this port and pressure maintained at $14 \mathrm{mmHg}$. The laparoscope was introduced through the port and the retroperitoneum inspected. Additional ports were introduced by the closed technique, under direct laparoscopic vision. The 
2nd port $10 \mathrm{~mm}$ was introduced in the mid-axillary line a finger breadth above the iliac crest. The third port of $10 \mathrm{~mm}$ was placed at the lateral border of the ipsilateral psoas at the same hori-zontal level as the primary port. The fourth port (additional port) if needed can introduced in the anterior axillary line at the same horizontal level as the primary port if it is required, but we have not yet use it.

\section{Different Surgical procedures: Simple Nephrectomy}

Inclusion criteria

All benign diseases of the kidney that can result in a poor or nonfunctioning of the kidney like:

a) Huge or giant hydronephrosis.

b) Chronic pyelonephritis

c) Symptomatic renal cystic disease of dialysis,

Exclusion criteria

a) History of previous retroperitoneal surgery,

b) Spinal deformity

Procedure: The kidney was identified and the lower pole mobilized. Using an electrocautery dissecting probe/ harmonic scalpel, grasping forceps and tri fan retractor, the ureter was located close to the lower pole. The ureter was then dissected. By dissecting along the ureter, the renal pelvis and renal vessels could be identified and dissected. The renal artery was clipped and transected (two weck clips on the vascular stump and one on the renal side). The renal vein was clipped and in the same manner. The upper pole was dissected, and the adrenal gland was left in place. The kidney was completely separated. Subsequently an inci-sion was made extending the 2 nd port (port above the iliac crest) and right hand was introduced into the retroperitoneal space the specimen was delivered intact. A suction drain was introduced through the primary port-site and the port-sites and incised wound closed in layers.

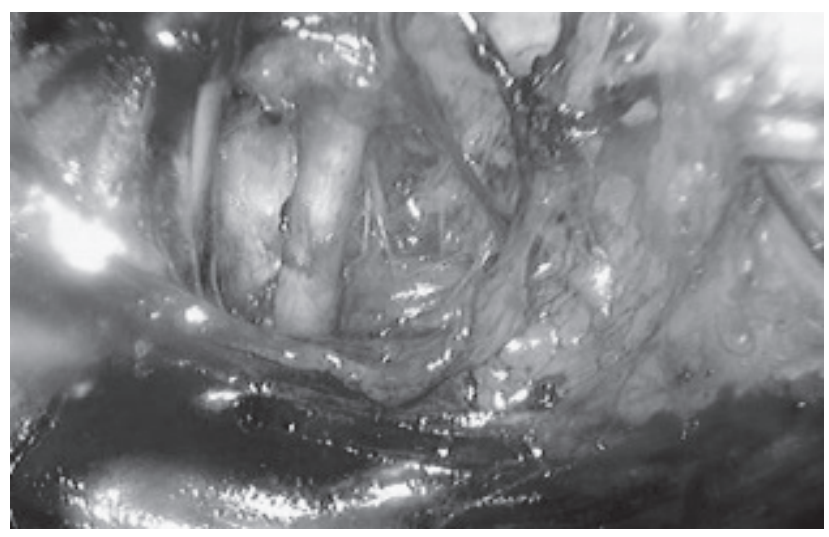

Fig.-5: Renal pedicle dissection during Left simple nephrectomy

\section{Radical Nephrectomy}

Inclusion criteria

a) Organ confined disease,

b) Tumor size $<7 \mathrm{~cm}$ in largest dimension,

c) No significant co-morbid illness,

Exclusion Criteria

a. Tumour size more than $7 \mathrm{~cm}$ or invading the renal capsule, venous involvement

b. History of previous retroperitoneal surgery,

c. Spinal deformity

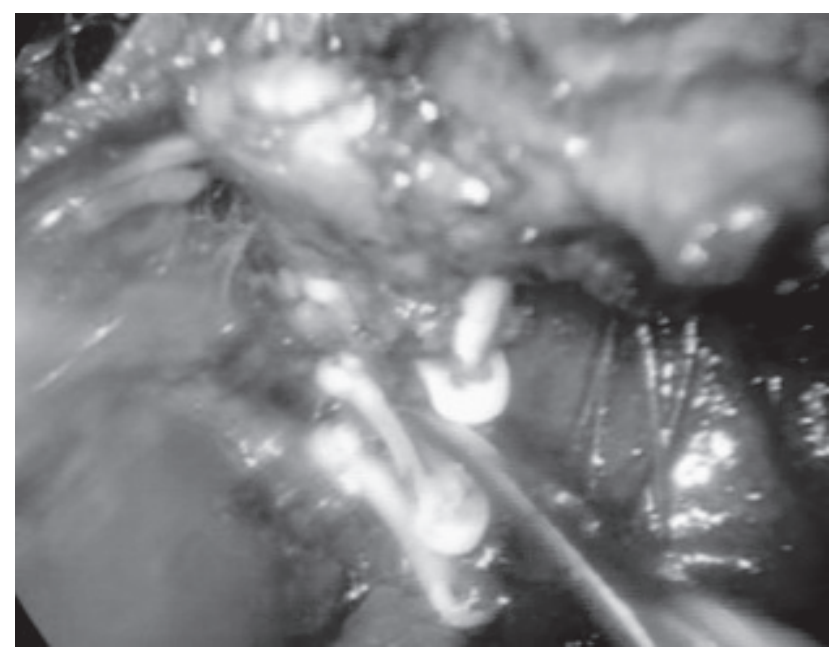

Fig.-6: Rt. Renal artery transection during right retroperitoneoscopic radical nephrectomy

\section{Procedure:}

The procedure was identical to simple nephrectomy, but dissection included the perirenal fat and the Gerota's fascia. The adrenal gland was left in place. The specimen was removed intact.

\section{Nephroureterctomy}

Inclusion criteria

TCC of the renal pelvis

TCC of the ureter

\section{Exclusion criteria \\ History of previous retroperitoneal surgery, Spinal deformity}

Procedure: This procedure is also similar to simple nephrectomy, but identification and clippling of the ureter is done first, then further dissection is carried out. After clipping and transection of the renal artery and vein, full mobilization of the kidney, kidney is delivered by extending the $2^{\text {nd }}$ port incision to $6 \mathrm{~cm}$, keeping the ureter with the kidney intact. Through this incision ureter was further mobilized upto its lower end. Urinary bladder was also mobilized. Ureter and cuff of the bladder was taken out and bladder was repaired. 


\section{Cyst Deroofing}

\section{Inclusion criteria}

- Simple Renal Cyst

- Size more than $5 \mathrm{~cm}$

- Symptomatic

- Persistent pain

- Obstruction to the upper urinary tract

- Increasing cyst size

\section{Exclusion Criteria}

a. APKD

b. Cyst of Bosniak type II or more

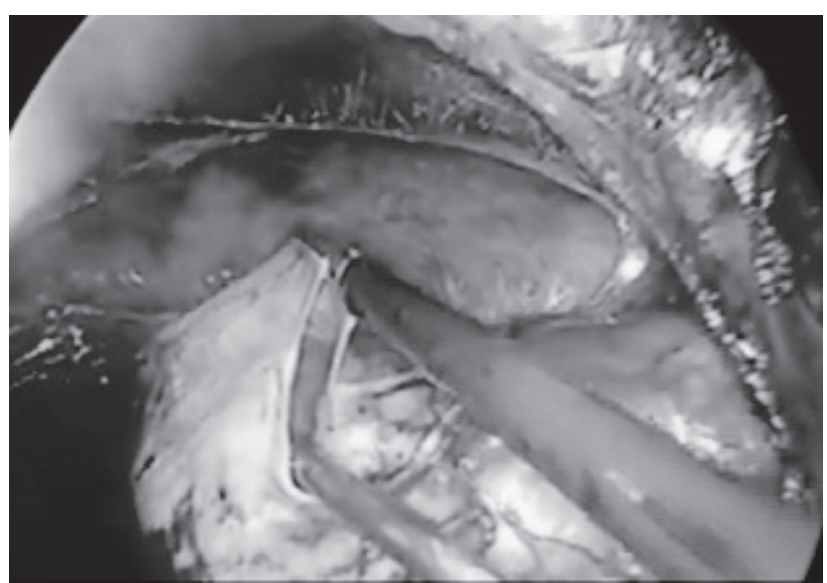

Fig.-7:Retroperitoneoscopic view of renal cyst de-roofing

Procedure: Perinephric fat was separated from the renal cyst by sharp and blunt dissection The cyst was excised, leaving only its base intact.

\section{Adrenalectomy}

Inclusion criteria:

Nonsecreting neoplasms measuring 4 to $7 \mathrm{~cm}$

Exclusion Criteria:

Proven malignant growth,

Tumour size more than $7 \mathrm{~cm}$.

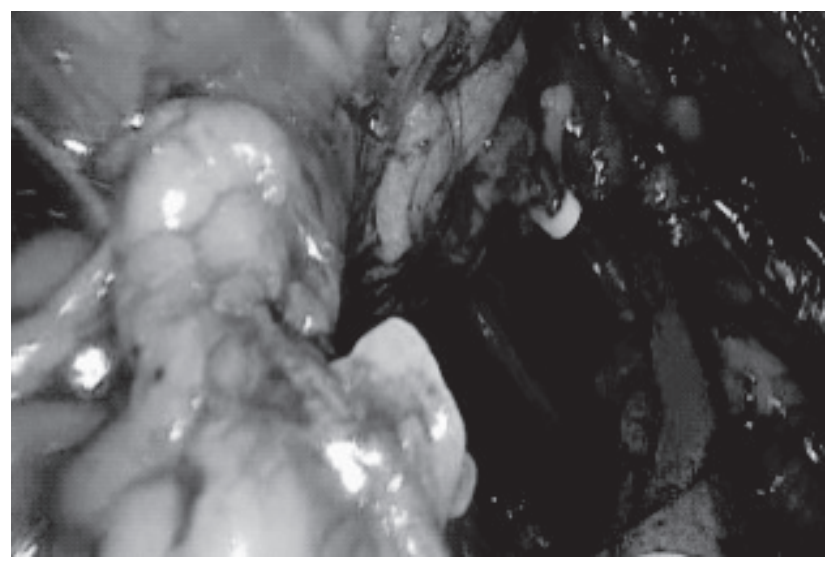

Fig.-8: Retroperitoneoscopic view of Left adrenalectomy

Procedure: The kidney was identified, and the upper pole was mobilized. The anterior face of the kidney was mobilized, and the inferior vena cava on the right side and renal vein on the left side was identified. The adrenal vein was secured by ligature clips and transected before mobilization of the adrenal gland. The adrenal gland was dissected free of the diaphragm and kidney. The adrenal arteries were coagulated with harmonic scalpel and clipped before transection. The adrenal gland was removed in intact.

\section{Retroperitoneoscopic Pyeloplasty:}

\section{Inclusion criteria}

- Age more than 18 years,

- UPJ Obstruction confirmed with IVU/CT urogram and DTPA renogram

- Large Extra renal pelvis

- No significant co-morbid illness and,

\section{Exclusion criteria}

- Age less than 18 yrs.

- History of previous renal surgery
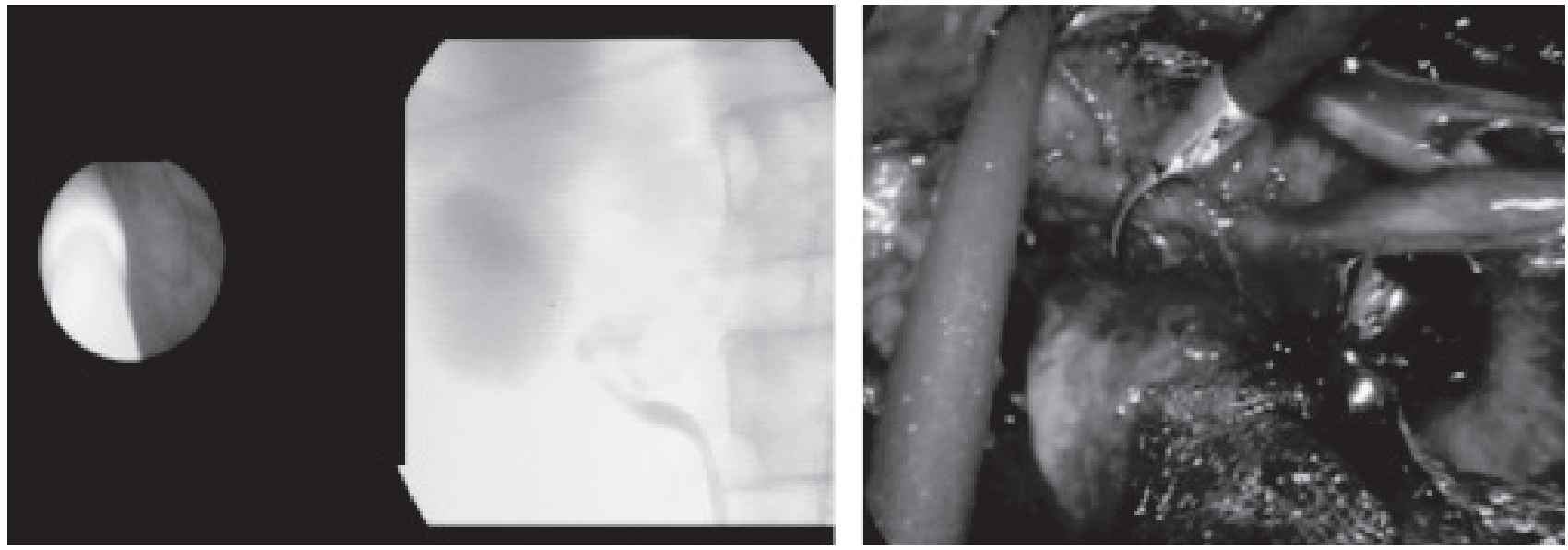

Fig.-9: RGP and Retroperitoneal dissection for pyeloplasty 

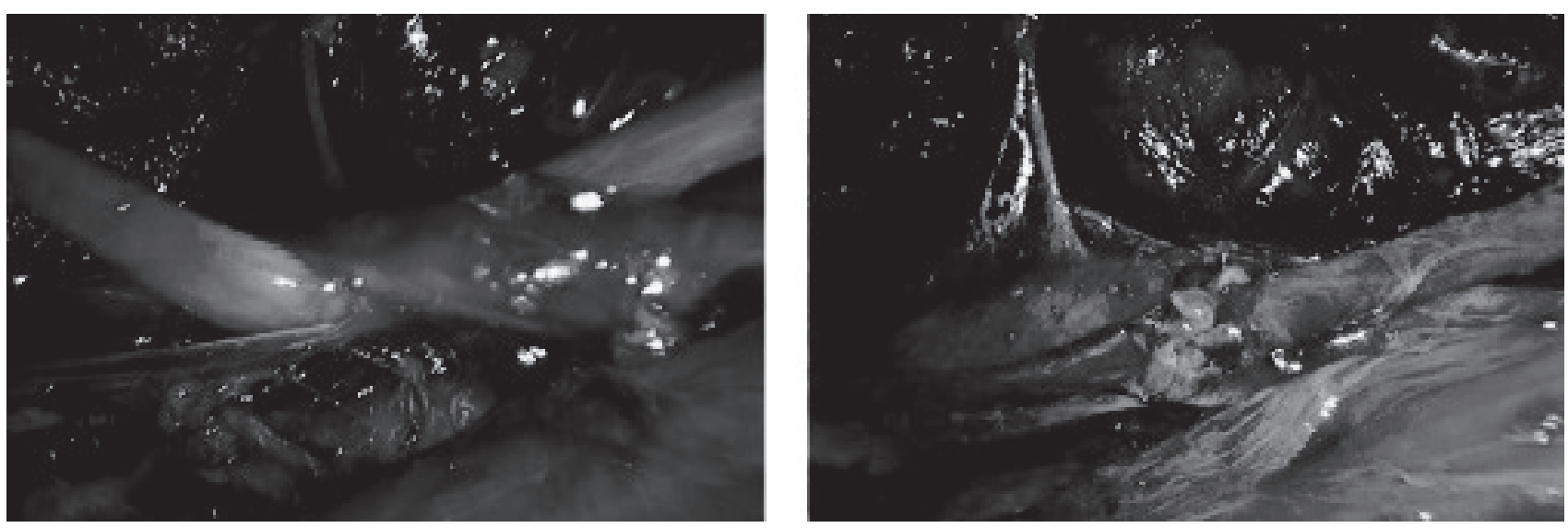

Fig.-10: Retrocaval ureter, and its transposition

\section{Procedure:}

Retrograde pyelography and J-J stenting was done. After all port placement ureter was identified and traced uptopelviureteric junction. Mobilization of the renal pelvis and adjacent ureter was done. Pelvis was transected,spatulation of the ureter was done. Redundant renal pelvis was excised. Ureteropelvic anastomosis was done over $\mathrm{J}-\mathrm{J}$ stent.

\section{Transposition of The Retrocaval Ureter.}

\section{Inclusion criteria :}

Retrocaval ureter with recurrent mild to moderate right flank pain.

Retrocaval ureter with asymptomatic right hydronephrosis.

\section{Procedure}

Retrograde pyelography and J-J stenting was done. After creation of the retropneumoperitonium the perirenal fat was dissected to reveal the posterior surface of the mid and lower pole of the kidney. The dilated renal pelvis and the upper ureter were fully mobilized using both blunt and sharp dissection. Dissection proceeded downward along the proximal dilated ureter, and then the inferior vena cava (IVC) was identified. The upper ureter changed its way and passed behind the IVC, and then followed the lower ureter. The lower ureter ran on the left side of the IVC (Fig. 10). The mobilization of the lower ureter should be enough to facilitate tension-free ureteroureteral anastomosis. The upper ureter was transected where it starts to wind under the IVC. The retrocaval segment of the ureter was mobilized and transposed anterior to the IVC. Reconstruction was carried out with freehand intracorporeal suture techniques over the J-J stent.

\section{Ureterolithotomy:}

Inclusion criteria

- Age more than 18 years,

- Large (1.5 cm or more) impacted upper and mid ureteric stone

- Failed ESWL

\section{Exclusion criteria}

Previous retroperitoneal surgery

Spinal deformity

\section{Procedure}

Gerota's fascia was divided and ureter was immediately identified and traced to the level of the stone. Often, inflammation around the ureter was found and careful use of monopolar and bipolar energy should control bleeding and at the same time avoid damage to the ureter. An indigenously prepared knife was introduced to make aureterotomy directly on the stone. Extension of ureterotomy was performed by a pair of endoscissors and stone was extracted. Stone was placed into a glove finger and removed through one of the ports. Placement of double $\mathrm{J}$ stent is optional.

\section{Results}

\section{Table-I}

Distribution of the patient according to the procedures

\begin{tabular}{lc}
\hline Treatment Methods & No of Patient \\
\hline Simple nephrectomy & 10 \\
Radical nephrectomy & 09 \\
Nephroureterctomy, & 08 \\
Adrenalectomy & 01 \\
Decortication of renal cyst & 11 \\
Pyeloplasty & 06 \\
Transposition of retrocavalureter & 06 \\
Ureterolithotomy, & 11 \\
\hline Total & 62 \\
\hline
\end{tabular}


Table-II

Simple Nephrectomy $(n=10)$

\begin{tabular}{|c|c|c|c|c|c|c|}
\hline SI. No & $\begin{array}{l}\text { No of } \\
\text { Patient }\end{array}$ & Indication & $\begin{array}{c}\text { Duration } \\
\text { operation }\end{array}$ & $\begin{array}{l}\text { Blood } \\
\text { loss }\end{array}$ & Complication & $\begin{array}{c}\text { Hospital stay } \\
\text { (After operation) }\end{array}$ \\
\hline 1. & 06 & $\begin{array}{l}\text { HDN due to } \\
\text { PUJO }\end{array}$ & $\begin{array}{c}\text { 40-155min Mean } \\
97.5 \mathrm{~min}\end{array}$ & Negligible & None & 2-6days \\
\hline 2. & 03 & $\begin{array}{c}\text { Chronic } \\
\text { pyelonephritis }\end{array}$ & $\begin{array}{l}\text { 75-180 } \min \\
\text { Mean 127.5min }\end{array}$ & $\begin{array}{l}20 \text { to } 130 \mathrm{ml} \\
\text { Mean } 75 \mathrm{ml}\end{array}$ & $\begin{array}{c}\text { Conversion in } \\
\text { one patient }\end{array}$ & 3-7 days \\
\hline 3. & 01 & $\begin{array}{l}\text { Symptomatic renal } \\
\text { cystic disease } \\
\text { of dialysis }\end{array}$ & $115 \mathrm{~min}$ & $35 \mathrm{ml}$ & None & 5 days \\
\hline
\end{tabular}

Average kidney size was $85 \mathrm{~mm}$ (range 50 to 1720), average operating time 110 minutes (range 40 to 180) and average hospital stay 3-7 days (range 2 to 7 ). Average blood loss was $55 \mathrm{~mL}$.

Table-III

Radical Nephrectomy(n=9):

\begin{tabular}{|c|c|c|c|c|c|c|}
\hline$\overline{\text { No }}$ & Gender/Age & Indication & Duration & $\begin{array}{l}\text { Amount of } \\
\text { blood loss }\end{array}$ & Complications & $\begin{array}{l}\text { Hosp. stay (After } \\
\text { operation) (Days) }\end{array}$ \\
\hline 1. & Female/54y & RCC Lt (55mm) & $185 \mathrm{~min}$ & $110 \mathrm{ml}$ & & 3 \\
\hline 2. & Male/60y & RCC Rt (60mm) & $115 \mathrm{~min}$ & Very minimum & & 5 \\
\hline 3. & Male/65y & RCC Rt (72mm) & $155 \mathrm{~min}$ & Very minimum & & 3 \\
\hline 4. & Male/45y & RCC. Rt (65mm) & $145 \mathrm{~min}$ & $200 \mathrm{ml}$ & & 6 \\
\hline 5. & Female/60y & RCC Lt. (62mm) & $130 \mathrm{~min}$ & $40 \mathrm{ml}$ & Peritoneal rent & 3 \\
\hline 6. & Male/49y & RCC. Rt (67mm) & $145 \mathrm{~min}$ & $60 \mathrm{ml}$ & & 4 \\
\hline 7. & Male/57y & RCC Lt. (59mm) & $155 \mathrm{~min}$ & $65 \mathrm{ml}$ & & 4 \\
\hline 8. & Male/61y & RCC Rt. (53mm) & $135 \mathrm{~min}$ & Very minimum & Conversion & 3 \\
\hline 9. & Male/66y & RCC Rt. (65mm) & $110 \mathrm{~min}$ & $95 \mathrm{ml}$ & & 3 \\
\hline
\end{tabular}

Right sided involvement was more than left side (10 and 05 respectively). Average kidneytumour size 64mm (range 48 to $73 \mathrm{~mm}$ ), average operating time $145 \mathrm{~min}$ (Range 130 to 220), and average hospital stay 3.6 days, Average blood loss was $40 \mathrm{ml}$.

Table-IV

Nephroureterctomy $(n=8)$ :

\begin{tabular}{lccccc}
\hline $\begin{array}{l}\text { No of } \\
\text { patient }\end{array}$ & Indication & Site & $\begin{array}{c}\text { Duration of } \\
\text { operation }\end{array}$ & Blood loss & Complication \\
\hline 5 & TCC of the & RT-3 & $90-155$ min & 50 to $160 \mathrm{ml}$ & None \\
Renal Pelvis & Lt-2 & Mean 125 & Mean $127 \mathrm{ml}$ & \\
& RCC of the Ureter & Rt-1 & $75-180$ min & 20 to $130 \mathrm{ml}$ & $\begin{array}{c}\text { Conversion in } \\
\text { Upper }\end{array}$ \\
& Middle & Rt-1 & Mean130 & Mean $80 \mathrm{ml}$ & 1 patient \\
& Lower & Lt-1 & & & \\
\hline
\end{tabular}

Most of the tumour involves the renal pelvis. Average operating time was $130 \mathrm{~min}$, average blood loss was $127 \mathrm{ml}$ in renal pelvis tumour and $80 \mathrm{ml}$ in ureteral tumour. One needed conversion due difficult dissection. 
Table-V

Renal CystDeroofing ( $n=11)$

\begin{tabular}{|c|c|c|c|c|c|c|c|}
\hline$\overline{\text { SI no. }}$ & Indication & Location & Side & $\begin{array}{c}\text { Duration of } \\
\text { operation }\end{array}$ & Blood loss & Complication & $\begin{array}{c}\text { Hosp. stay } \\
\text { (After operation) }\end{array}$ \\
\hline 1. & $\begin{array}{l}\text { Increasing } \\
\text { cyst size-05 }\end{array}$ & $\begin{array}{l}\text { Lower } \\
\text { pole-8 } \\
\text { Middle } \\
\text { pole-3 } \\
\text { Upper } \\
\text { pole-0 }\end{array}$ & $\begin{array}{l}\text { Rt.- } 07 \\
\text { Lt.- } 04\end{array}$ & $\begin{array}{c}\text { 35-70 min } \\
\text { Mean } 46.0 \\
\text { min }\end{array}$ & Negligible & None & 3-6 days \\
\hline 2. & Obstruction of UUT-02 & & & & & & \\
\hline 3. & Flank pain or discomfort-04 & & & & & & \\
\hline
\end{tabular}

The main reason of operation was increasing size of the cyst and flank pain and discomfort. Number of lower polar cyst was predominant. Average operating time was 46 minutes no significant blood loss or complications were noted.

\section{Adrenalectomy: $(n=1)$}

We have so far done only one retroperitoneoscopicadrenalectomy. It took 123 minutes, with minimal blood loss and post-operative hospital stay was 3 days

Table-VI

Ureterolithotomy $(n=11)$

\begin{tabular}{|c|c|c|c|c|c|c|c|}
\hline$\overline{\text { SI no. }}$ & Indication & Location & Side & $\begin{array}{c}\text { Duration of } \\
\text { operation }\end{array}$ & Blood loss & Complication & $\begin{array}{c}\text { Hosp. stay } \\
\text { (After operation) }\end{array}$ \\
\hline 1. & $\begin{array}{l}\text { Impacted } \\
\text { Stone-7 }\end{array}$ & $\begin{array}{l}\text { Upper } \\
\text { Ureter-08 } \\
\text { Mid. Ureter-03 }\end{array}$ & $\begin{array}{l}\text { Rt.- } 06 \\
\text { Lt.- } 05\end{array}$ & $\begin{array}{l}\text { 45-105min } \\
\text { Mean 67min }\end{array}$ & Negligible & None & 2-5 days \\
\hline 2. & Failed ESWL-4 & & & & & & \\
\hline
\end{tabular}

The principal cause for ureterolithotomy was impacted stone, Upper ureteric stone was more than left ureteric stone. Mean operating time was 67 minutes, hospital stay time after operation was $2-5$ days.

Table-VII

Retrocaval Ureter $(n=6)$

\begin{tabular}{|c|c|c|c|c|c|c|}
\hline$\overline{\text { No }}$ & Gender/Age & Presentation & Duration & $\begin{array}{l}\text { Amount of } \\
\text { blood loss }\end{array}$ & Complications & $\begin{array}{l}\text { Hosp. stay (After } \\
\text { operation) (Days) }\end{array}$ \\
\hline$\overline{1 .}$ & Female/54y & Mild to moderate & $\begin{array}{l}220 \text { minright } \\
\text { flank pain }\end{array}$ & Very minimum & None & 4 days \\
\hline 2. & Male/60y & $\begin{array}{l}\text { Asymptomatic, incidentally } \\
\text { discovered to have right } \\
\text { hydronephrosis on USG }\end{array}$ & $117 \min$ & Very minimum & None & 3 Days \\
\hline 3. & Male/65y & $\begin{array}{l}\text { Mild to moderate } \\
\text { right flank pain }\end{array}$ & $105 \mathrm{~min}$ & $\begin{array}{l}\text { Very } \\
\text { minimum }\end{array}$ & None & 5 Days \\
\hline 4. & Male/45y & $\begin{array}{l}\text { Mild to moderate right } \\
\text { flank pain }\end{array}$ & $145 \mathrm{~min}$ & $200 \mathrm{ml}$ & None & 7 Days \\
\hline 5. & Female/60y & $\begin{array}{l}\text { Asymptomatic, incidentally } \\
\text { discovered to have right } \\
\text { hydronephrosis on USG }\end{array}$ & $115 \mathrm{~min}$ & Very minimum & None & 4 days \\
\hline 6. & Male/49y & $\begin{array}{l}\text { Mild to moderate } \\
\text { right flank pain }\end{array}$ & $110 \mathrm{~min}$ & Very minimum & None & 3 days \\
\hline
\end{tabular}

Most of the patient presented as mild to moderate right flank pain, highest operating time was 220 minutes, it was in the $1^{\text {st }}$ case, about $200 \mathrm{ml}$ of blood loss observed in one patient, no leakage was seen in any patient, maximum hospital stay after operation was 7 days. 
Table-VIII

Pyeloplasty $(n=6)$

\begin{tabular}{llllll}
\hline SI no. & Side & $\begin{array}{l}\text { Duration of } \\
\text { operation }\end{array}$ & $\begin{array}{c}\text { Blood } \\
\text { loss }\end{array}$ & Complication & Hosp. stay \\
\hline 1. & Rt.- 04 & 87-183 min & Negligible & Minimal leakage- 1 pt & 4-7 days(Avg: 4.6 days) \\
2. & Lt.- 02 & Mean 123 min & & & \\
\hline
\end{tabular}

Out of 11 patients 07 was on the right side, mean operating time was 123 minutes, minimal leakage was found in one patient, average hospital stay after operation was 4.6 days.

\section{Complications}

Conversion from the laparoscopic procedure to open surgery was required in three cases. We observed two peritoneal tear, which was sutured peroperatively. Peristalsis and bowel movements returned rapidly in every case. Pain was evaluated on a visual analog scale. Ketorolac was routinely administered after surgery in the form of its injection and oral form except the ESRD patient where pathedine was used.

\section{Comment}

Difficulty in obtaining a sufficient retroperitoneal working space was the main obstacle to the development of retroperitoneoscopy. In 1983, Wickham and Miller' tried to reach the kidneys through a retroperitoneal access in Cadavar, with little success. Kerblet al[2] proposed retroperitoneal dissection with $\mathrm{CO}_{2}$, but this was not sufficient to separate the tissue. In 1993, Gaur described a retroperitoneal balloon dissection that renewed interest in retroperitoneoscopy. In 1994, Rassweileret al[3] modified Gaur's method into a hydraulic balloon dissection technique of the retroperitoneum. The advantage of hydraulic balloon dissection is based on the incompressibility of normal saline, which allows better dissection. In 1994, Barretoet al[4] performed eight retroperitoneoscopieson 7 patients. Balloon dissection was used for the first 4 patients, but the retroperitoneal space was created by insufflation only in the subsequent 3 patients. In our experience, the balloon dissection procedure is very much suitable space. The main need is to create a sufficient working space for insertion of the laparoscope. After incision in the upper lumbar triangle, the retroperitoneal space was created by blunt dissection with the index finger and completed by insufflation with balloon dissector; the space was adequate for insertion of the other trocars under direct vision. In 1991, the first retroperitoneoscopic nephrectomy was performed by Gaur et al[5] for chronic pyelonephritis. In 1993, using the same procedure, Gill et al. carried out the first partial nephrectomy[6].
Retroperitoneoscopic procedures subsequently multiplied, with radical nephrectomies, nephroureterectomies, nephropexy, and cyst excision. Thereafter series of retroperitoneoscopic nephrectomy have been published [7-17].

In our series the mean operating time varies, depending upon the complexity of operations, as below as $35 \mathrm{~min}$. in renal cyst deroofing to $220 \mathrm{~min}$. in transposition of retrocavalureter. Blood loss ranged from 0 to $200 \mathrm{~mL}$, and the conversion level to open surgery was three out of 62 patients. The hospital stay ranged from 2 to 7 days.

We had previously performed a few nephrectomy andadrenalectomyby transperitoneal laparoscopy, which is indispensable before practicing retroperitoneoscopy. The morbidity rate for retroperitoneoscopy was low. Carbon dioxide absorption was negligible, and hypercapniawas avoided by close ventilatory management.

Complications were few. Two peritoneal tear noted and sutured instantly. No pneumothorax or pneumomediastinum occurred [18]. Renal vein was torn in one simple nephrectomy case due to accidental injury from the tip of the harmonic scalpel and rapid conversion was done. Other two cases of radical nephrectomy and nephroureterctomy needed conversion due to difficult dissection. The global complication rate for renal surgery, including the radical nephrectomies and the partial nephrectomy, was $8.3 \%$. We observed minimal complications in our series. Whereas a complication rate of $12 \%$ has been reported for transperitoneaIprocedures[19]. These results are encouraging and can be explained by the direct approach to the kidney and the adrenal gland. This approach avoids discomfort to intra-abdominal organs and the need for extensive colonic dissection. The risk of bowel or vascular injury is avoided during insufflation. 


\section{Conclusions:}

Retroperitoneoscopy is a suitable laparoscopic procedure for renal, ureteral and adrenal surgery. Early results are encouraging and seem to be better than those for transperitoneal laparoscopy. Because the complication rate and operating time are acceptable, we will use this procedure more frequently as our experience evolves.

\section{References:}

1. Gupta NP, Hemal AK, Mishra S, Dogra PN, Kumar R. Outcome of retroperitoneoscopic nephrectomy for benign nonfunctioning kidney: a single-center experience. J Endourol. 2008 Apr. 22(4):693-8.

2. Wickham JEA, and Miller RA: Percutaneous renal access, in Wickham JEA (Ed) : Percutaneous Renal Surgery. New York, Churchill Livingstone, 1983, vol. 2, pp 33-39.

3. Gaur DD: Laparoscopic operative retroperitoneoscopy: use of a new device. J Urol 148: 1137-1139, 1992.

4. Barreto H, Doublet JD, Peraldi MN, Gattegno B, and Thibault $P$ : Kidney surgery using lumbar endoscopy: initial experiences ProgUrol 5: 384389, 1995.

5. Gaur DD, Agarwal DK, and Purohit KC: Retroperitoneal laparoscopic nephrectomy: initial case report. J Urol 149: 103-105,1993.

6. Gill IS, Delworth MG, and Munch LC: Laparoscopic retroperitoneal partial nephrectomy. J Urol 152: 1539-1542,1994.

7. Kerbl K, Clayman RV, McDougall EM, and Kavoussi LR: Laparoscopic nephrectomy: the Washington University experience. Br J Urol 73: 231-236, 1994.

8. Nicol DL, Winkle DC, Nathanson LK, and Smithers BM: Laparoscopic nephrectomy for benign renal disease. Br J Urol 73: 237-241, 1994.

9. Katoh $\mathrm{N}$, Ono $\mathrm{Y}$, Kinukawa $\mathrm{T}$, Sahashi $\mathrm{M}$, and Ohshima S: Efficacy of a retroperitoneal approach in a laparascopic nephrectomy for benign renal disease (abstract). J Urol 153: 479A, 1995.

10. Eraky I, el-Kappany H, Shamaa MA, and Ghoneim MA: Laparoscopic nephrectomy: an established routine procedure. J Endourol 8: 275-278, 1994.
11. Rassweiler J, Henkel TO, Potempa DM, Coptcoat MJ, Miller K, Preminger GM, and Alken P: Transperitoneal laparoscopic nephrectomy: training, technique, and results. J Endour01 7: 505516, 1993.

12. Mandressi A, Buizza C, Antonelli D, Chisena S, and Servadio G: Retroperitoneoscopy. Ann Uro129: 91-96, 1995.

13. Gagner M, Lacroix A, and Bolte E: Laparoscopic adrenalectomy in Cushing's syndrome and pheochromocytoma (letter). N Engl J Med 327: 1033, 1992.

14. Higashihara E, Tanaka Y, Horie S, Agura S, Nutahara K, Minowada S, and Aso Y: Laparoscopic adrenalectomy: the initial 3 cases. J Urol 149: 973976, 1993.

15. Fernandez-Cruz L, Benarroch G, Torres E, Astudillo E, Saenz A, and Taura P: Laparoscopic approach to the adrenal tumors. J LaparoendoscSurg 3: 541-546, 1993.

16. Albala DA, and Prinz RA: Laparoscopic adrenalectomy: results of eight patients (abstract). J Urol 151: 393A, 1994.

17. Suzuki K, Kageyama S, Ueda D, Ushiyama T, Kawabe K, Tajima A, and Aso Y: Laparoscopic adrenalectomy: clinical experience with 12 cases. J Urol 150: 1099-1102, 1993.

18. Wolf JS Jr, Monk TG, McDougallWolf JS Jr, Monk TG, McDougall EM, McClennan BL, and Clayman RV: The extraperitoneal approach and subcutaneous emphysema are associated with greater absorption of carbon dioxide during laparoscopic renal surgery. J Urol 154: 959-963, 1995.

19. Gill IS, Kavoussi LR, Clayman RV, Ehrlich R, Evans R, Fuchs G, Gersham A, Hulbert JC, McDougall $E M$, Rosenthal $T$, et al: Complications of laparoscopic nephrectomy in 185 patients: a multiinstitutional review. J Urol 154: 479-483,1995.

\footnotetext{
Abbreviations:

APKD : Adult polycystic kidney disease

DTPA : Diethylene Triamine pentaacetic acid

FNAC : Fine needle aspiration cytology

PUJO : Pelviureteric junction obstruction

TCC : Transitional cell carcinoma
}

Editorial Comment: Principal author of this article has been awarded 'Maj. Gen (Rt.) KM Siraj Jinnat Memorial Lecture Award' 2016 for his initiative and innovative work on Retroperitoneoscopic Urologic surgery. This article represents his works. 